\title{
The evaluation of psychogenic non-epileptic seizures (PNES) cases with saline injection method in video-EEG monitorization unit
}

\author{
Avaliação de casos de crises não epilépticas psicogênicas (CNEPs) pelo método de \\ injeção de solução salina em unidade de monitoramento por vídeo-EEG \\ ibrahim BORA', Aylin Bican DEMIR¹, Dursun CEYLAN²
}

\begin{abstract}
Background: It has been reported that 10 to $30 \%$ of patients sent to epilepsy centers with a diagnosis of refractory epilepsy are diagnosed with psychogenic non-epileptic seizure (PNES). A wide variety of provocative methods are used to assist PNES diagnosis. Objective: To investigate the effect of seizure induction on the diagnosis and prognosis of PNES. Methods: We retrospectively examined 91 patients with PNES complaints in our video-EEG laboratory. Intravenous saline was administered to all patients for induction of seizures. Results: Saline injection was performed in 91 patients referred to our EEG lab with PNES initial diagnosis, 57 of whom were female and 34 male. Saline injection triggered an attack in 82 patients (90\%). Conclusions: In this study we have concluded that provocative methods are practical, cheap and, most of all, effective for patient diagnosis. In clinical practice, explaining the diagnosis is the first and most important step of the treatment, and careful patient-doctor communication has a positive impact on patient prognosis.
\end{abstract}

Keywords: Seizures; Saline Solution; Electrocorticography.

\section{RESUMO}

Antecedentes: Há relatos de que 10 a 30\% dos pacientes com epilepsia refratária enviados a centros de epilepsia são diagnosticados com crise não epiléptica psicogênica (CNEP). Uma ampla variedade de métodos provocativos é usada para auxiliar no diagnóstico de CNEP. Objetivo: Investigar o efeito da indução de convulsões no diagnóstico e no prognóstico de CNEP. Métodos: Examinamos 91 pacientes com queixas de CNEP em nosso laboratório de vídeo-EEG. Foi administrada solução salina intravenosa a todos os pacientes para indução de convulsões. Resultados: A injeção de solução salina foi realizada em 91 pacientes com diagnóstico inicial de CNEP encaminhados ao nosso laboratório de EEG, 57 dos quais eram mulheres e 34 homens. A injeção de solução salina desencadeou um ataque em 82 pacientes (90\%). Conclusões: Neste estudo, concluímos que os métodos provocativos são práticos, baratos e, acima de tudo, eficazes para o diagnóstico de pacientes. Na prática clínica, a explicação do diagnóstico é a primeira e mais importante etapa do tratamento, e a comunicação cuidadosa entre médicos e pacientes tem um impacto positivo em seu prognóstico.

Palavras-chave: Convulsões; Solução Salina; Eletrocorticografia.

\section{INTRODUCTION}

The psychogenic non-epileptic seizure (PNES) is a clinical condition that is similar to epileptic seizure, being time-limited, sudden, paroxysmal, motor, sensory, and presents with autonomic and/or cognitive signs and symptoms, but is not accompanied by ictal epileptiform activity ${ }^{1}$. Epilepsy has been reported to be associated with PNES in $10.7 \%$ of patients ${ }^{2}$. PNES was determined in $17-30 \%$ of patients referred to tertiary-care epilepsy centers due to persistent seizures. In the general population, the prevalence of PNES varies from $1 / 3,000$ to $1 / 50,000^{3,4}$. It has been reported that $75-85 \%$ of patients are female and the onset is between the 3rd and 4th decade of life ${ }^{5}$.

Many terms such as pseudoseizures, hysterical epilepsy, pseudoepileptic seizures, psychogenic seizures, and functional seizures are used to describe this condition in the literature,

'Bursa Uludag University, Medical Faculty, Department of Neurology, Epilepsy and Sleep Unit, Bursa, Turkey.

²Bilecik State Hospital, Bilecik, Turkey.

IB (D) https://orcid.org/0000-0002-9435-6037; ABD (D) https://orcid.org/0000-0001-6739-8605; DC (1) https://orcid.org/0000-0001-5110-1248

Correspondence:Aylin Bican Demir; Email:aylinbican@mynet.com/aylinbd@uludag.edu.tr.

Conflict of interest: There is no conflict of interest to declare.

Authors' contributions: IB, ABD, DC: idea/concept desıgn; ABD, iB: data collection and/or analysis; ABD, DC: data evaluation, literature search, article writing and critical review.

Received on November 26, 2020; Received in its final form on April 13, 2021; Accepted on April 24, 2021. 
but the term psychogenic non-epileptic seizure is still widely used. PNES is often misdiagnosed as epilepsy. PNES is often diagnosed in epilepsy centers using video-EEG Monitoring (VEM), although diagnosis often requires a multidisciplinary approach. Although the pathophysiology of PNES is not yet clearly understood, it is known not to have a neurobiological origin like epileptic seizures ${ }^{6}$.

PNES is more predominant in the female sex. Although the reason for this is not yet fully known, evidence suggests that there may be intrinsic functional connectivity differences in brain regions responsible for emotional and cognitive functions ${ }^{7}$. PNES is commonly confused with epilepsy, resulting in a diagnostic delay of 7 to 10 years 8 . Misdiagnosed PNES patients are unnecessarily prescribed multiple high-dose antiepileptic drugs (AEDs) with potential adverse effects and teratogenicity, and patients with prolonged seizures are unnecessarily intubated for pharmacologic sedation ${ }^{9,10}$. Moreover, these patients undergo unnecessary diagnostic tests and hospital admissions. Considering status epilepticus, even unnecessary IV treatment is performed in intensive care units. It is of great importance that differential diagnosis is done at the right time and in the right manner ${ }^{11}$. The golden standard in the differential diagnosis of PNES is to observe patients' seizures with a video-EEG monitoring unit ${ }^{12}$.

Although the ethical aspect is debated, various induction techniques are used to aid an early diagnosis of PNES, especially when long-term VEM cannot be applied. Although, the frequency of seizures varies in each patient, it may sometimes be necessary to provoke seizures using induction methods. There are many induction techniques. Routine sleep deprivation, hyperventilation and photic stimulation can be cited as an examples. Other methods such as massage application to the temporal region, verbal suggestion, hypnosis, diapason vibration, and saline injection are also used ${ }^{13}$. These provocation tests have facilitated making the correct diagnosis in patients who have few seizures, in whom a definite diagnosis cannot be made by interictal EEG, and in whom there is a psychiatric history that may indicate PNES ${ }^{14}$. Therefore, the length of hospital stay and the cost of diagnosis and treatment have been significantly reduced with these simple methods of obtaining the correct diagnosis. Of course as with all tests, there can be false-positives and false-negatives.

Subjecting patients to unnecessary drugs and stigmatization by society for a long time jeopardizes social bonds, which can have serious consequences. Therefore, performing seizure induction tests has been beneficial for patients ${ }^{15,16}$. However, the best type of induction method and its effectiveness is not known ${ }^{17}$.

\section{METHODS}

In this study, we investigated the results of saline intravenous (IV) injection (IV) after consent by the patient or their relatives. Patients who were admitted in the VEM Unit at the
Neurology Clinics in Uludag University and who were thought to have had PNES were included. In the VEM room, patients were connected to a 10-20 electrode system. Patients who had a seizure during simultaneous video recording were asked questions during the seizure and were told keywords to be asked later. Saline injection was carried out by an experienced doctor who followed all patients. In patients who were hospitalized in the VEM unit and did not have spontaneous seizures for 2-3 days, seizures were induced with $2 \mathrm{cc}$ saline injection. The patients and their relatives were appropriately informed that this procedure would be performed to establish a definite diagnosis.

After the seizure episode, the EEG of the patient was evaluated by the epileptologist and the relatives of the patient were shown the seizure episode and asked whether it resembled previous seizure episodes. Patients were questioned whether they remembered the given key words after the episode. The same keywords were told to all patients. All seizures were evaluated by the same epileptologist based on seizure semiology together with the video scan and EEG.

Patients who had seizures after induction and in whom no ictal epileptiform activity or postictal changes were observed in EEG during the seizure period were defined as PNES. These patients were informed that no electrical changes were observed in the brain during the seizure, thus ruling out diagnosis of epilepsy (Figure 1A, B and C). They were told that the cause of the seizure could be sub-conscious or underlying mental disorders, and psychiatric consultation was strongly recommended. The study was approved by Bursa Uludag University Medical Research Ethics Committee.

\section{RESULTS}

Saline injection was applied to 91 patients (52 females) who were referred to the VEM unit with suspicion of PNES. After saline injection, seizures were observed in 82 patients (90\%). The mean time of saline injection was 52 hours (48 to 92). Patients were divided into three sub-groups after injection: group 1, 66 patients who had only PNES; group 2, 16 patients who had both PNES and real seizures, and group 3, 9 patients who had no seizure after saline injection.

The age of patients at seizure onset was 14-44 (mean 26.4) in group 1, 6-51 (mean 28.8) in group 2, and 16-46 (mean 24.1) in group 3. Patients' age, sex distributions, age of seizure onset, AED use, duration of AED use and whether they had psychiatric diagnosis are shown in Table 1 . There were risk factors in 25 (38\%) patients of group 1 and in 8 (50\%) of group 2. The most common risk factor in group 1 was fall and head trauma and in group 2 was febrile convulsion. In group 1, 52 (79\%) of the 66 patients were receiving (AED) treatment (39 monotherapy, 13 polytherapy). After diagnosis, drugs were reduced and ceased.

Follow up showed that 45 of the 66 patients in group 1 received psychiatric counseling and treatment, and 12 of 16 patients in group 2 and 5 of nine patients in group 3 received a psychiatric diagnosis and took appropriate medications. 


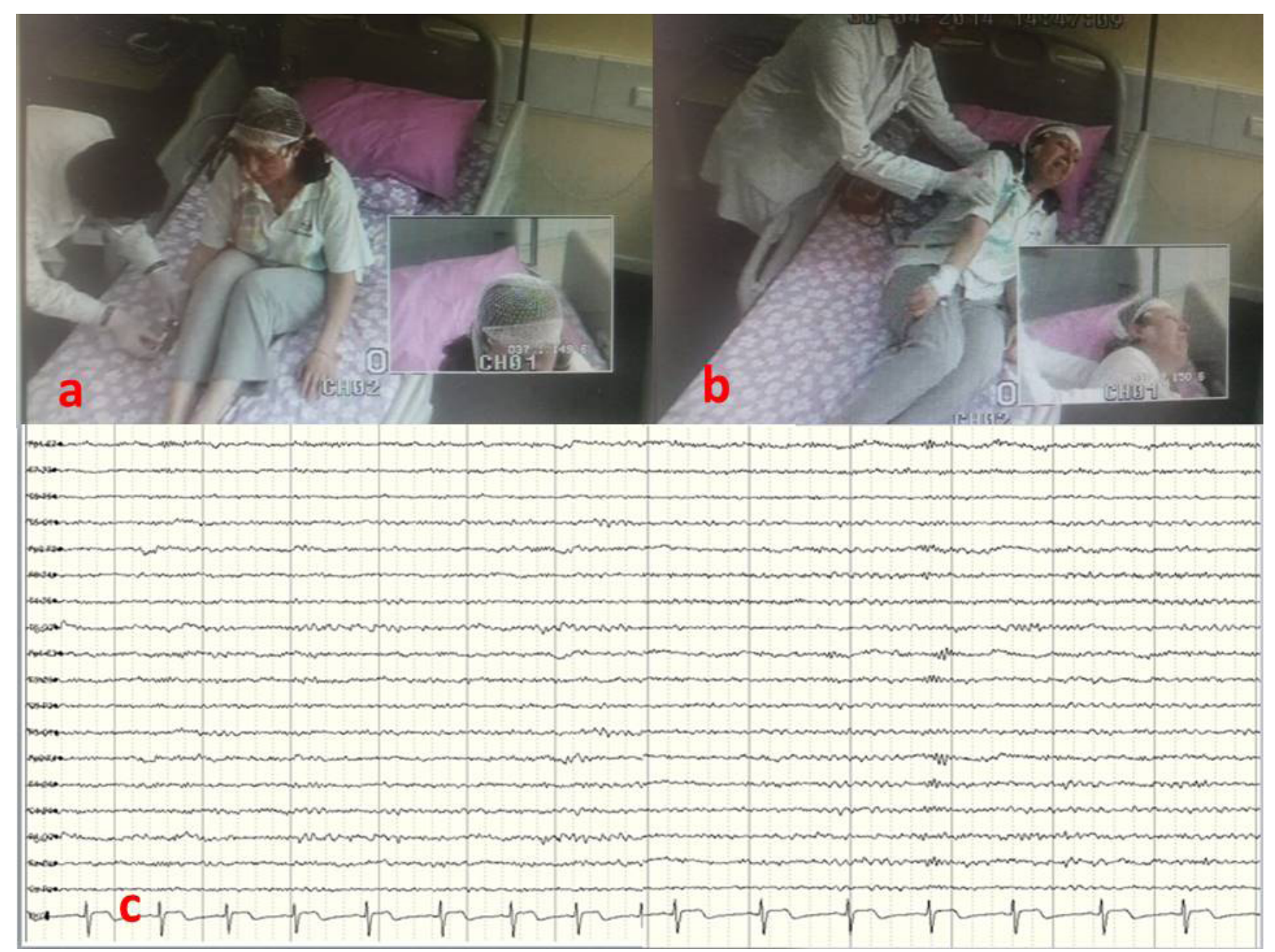

Figure 1. A: Physician giving saline to the patient and explaining the procedure; B: The patient has a psychogenic seizure after the procedure; C: Normal EEG of the patient during psychogenic seizure.

Table 1. Patient subgroups, demographic data, medical histories.

\begin{tabular}{|c|c|c|c|c|}
\hline Patients & & Group 1 & Group 2 & Group 3 \\
\hline \multirow{2}{*}{ Sex } & Female & 43 & 9 & 5 \\
\hline & Male & 23 & 7 & 4 \\
\hline Age & & 18-64 (mean 36.3) & 18-66 (mean 39.8) & 18-52 (mean 31.3) \\
\hline Seizure onset age & & $14-44$ (mean 26.4) & 6-51 (mean 28.8) & $16-46$ (mean 24.1) \\
\hline \multirow{3}{*}{ Use of AED } & Total & 52 & 16 & 6 \\
\hline & Monotherapy & 39 & 6 & 5 \\
\hline & Polytherapy & 13 & 10 & 1 \\
\hline AED use duration & & $\begin{array}{c}6-180 \text { month } \\
\text { (mean } 112 \text { months) }\end{array}$ & $\begin{array}{c}6-200 \text { month } \\
\text { (mean } 132 \text { months) }\end{array}$ & $\begin{array}{c}6-150 \text { month } \\
\text { (mean } 80 \text { months) }\end{array}$ \\
\hline \multirow{2}{*}{ Psychiatry diagnoses } & Yes & 45 & 12 & 5 \\
\hline & No & 21 & 4 & 4 \\
\hline Total & & 66 & 16 & 9 \\
\hline
\end{tabular}

\section{DISCUSSION}

The most important step in diagnosing PNES is the clinical suspicion. A good history obtained from an adult who has seen a seizure, the timing of the seizures, the relationship with psychogenic conditions, the duration and especially the characteristics are important in raising this suspicion. In patients with PNES, the delay in diagnosis is reported to be 7.2 years after the onset of symptoms ${ }^{18}$. The indication of aura, no specific symptoms, history of urinary incontinence, EEG misinterpretation, 
history of ictal injury, age of onset of seizure, and history of head trauma play an important role in delayed diagnosis. It was reported that preservation of awareness, frequent eye movements, and level of motor phenomena are the most significant semiological findings in favor of PNES, and opening and dilatation of pupils at seizure onset, postictal confusion/ sleep are characteristics of epileptic seizures ${ }^{8}$.

PNES is more frequent in females, and in $75-85 \%$, it occurs in the 3 rd and 4 th decades of life ${ }^{5}$. In our study, it affected women in the 2nd decade of life in $62.6 \%$, in groups 1,2 , and 3 , which is in agreement with literature.

A previous study reported that patients with PNES had seizures within 48 hours in $90 \%$ of cases and if no attack occurred after this period, induction could be performed ${ }^{19}$. In our study, induction was performed after an average of 52 hours in patients in whom no spontaneous seizure was observed.

In another study with patients with a possible pre-diagnosis of PNES induced with verbal suggestion and saline, 52 (72.2\%) of 72 patients had non-epileptic seizures ${ }^{20}$.

In our study, an attack occurred in 82 of 90 patients to whom induction was performed. The eyes of 21 patients were closed during the seizure, 15 patients were unresponsive during seizure, and responsiveness was protected in 14 patients. Thirty patients showed various motor symptoms (spasms in single or two or all extremities), two patients had only emotional symptoms, pelvic thrusting was observed in nine patients, and ictal and postictal crying in five patients.

In a study carried out by Bora et al, spontaneous seizures were recorded in 67 patients with PNES and catatonic and major motor movements were recorded in 27 patients (40\%), minor movement in 21 patients (31\%), and subjective symptoms in 19 patients $(29 \%)^{21}$. PNES was determined in 17 of 30 patients referred to tertiary care epilepsy centers due to resistant epilepsy'.

In a case series of PNES including nine cases, six patients were intubated with status epilepticus and followed up. The patients had repeated intravenous antiepileptic treatment since their seizures lasted a long time and there was a delay in seeing an epileptologist ${ }^{22}$.

It should be taken into consideration that PNES seizures can be accompanied by epileptic seizures. In this circumstance, it is extremely difficult and important to define PNES. The most important sign is unexpected unresponsiveness to proper drug treatment, as PNES may be the cause of this pseudo-resistance. Hence, seizure recordings must be held in patients under control follow up and each seizure should be redefined to prevent unnecessary AED dosage and combinations. In our study, epileptic seizures was accompanied by PNES in 16 of 91 patients.

The epileptic seizures of 16 patients were focal in 9 patients, focal+bilateral tonic clonic in 4 patients, and bilateral tonic clonic in 3 patients. The ictal EEG of these patients were evaluated as focal sharp wave, focal slow wave and generalized spike-slow wave activity, respectively.
The gold standard for diagnosing PNES seizures is the examination of long term $\mathrm{VEM}^{23,24}$. However, its routine application is limited due to the cost of examination and the duration of appointments that sometimes take months or years. Therefore, several epilepsy centers (39 to 73\%) use provocative methods to help diagnose $\mathrm{PNES}^{25}$.

The main purpose of induction tests is to support the diagnosis of PNES, decrease cost, and decrease the waiting time in VEM units ${ }^{26}$. Intravenous saline application, hyperventilation, photic stimulation, hypnosis or seizure provocation with suggestion methods have been used in many centers ${ }^{27-30}$.

Placebo infusions are occasionally used to induce psychogenic episodes. The saline provocation test is very useful in diagnosing PNES, particularly when the diagnosis remains uncertain or spontaneous episodes do not occur during monitoring ${ }^{31}$. However, the induction of seizures in still controversial ${ }^{25,27-29}$.

Those in favor of induction defend that this simple and cheap method can establish the correct diagnosis and avoid the use of incorrect treatments for years, which are armful to patients ${ }^{25}$. Given that long term video EEG assessment is limited in many countries, patients can remain with an incorrect diagnosis, and the evaluation of candidates for epilepsy surgery in these centers can be delayed.

Those against the application of provocative tests defend that such tests can also provoke epileptic seizures. In addition, there is suspicion about the tests' reliability and the patientphysician relationship may be affected. Primary generalized epilepsies can be provoke by intermittent photic stimulation, but it is extremely easy to define these seizures by typical EEG finding. Since there is no consensus on the ethics of using induction techniques in the diagnosis of PNES, it is not easy to decide whether to do it or not. However, the most controversial method of induction is saline injection ${ }^{32}$.

In respect of the test reliability, observing a seizure with induction is not sufficient to diagnose a patient with PNES. Epilepsy and PNES coexistence is reported to be between 5\% and $40 \%$ in different studies ${ }^{30,33-35}$. In addition, the fact that induction is negative does not rule out PNES diagnosis. It was reported in different studies that no seizure is observed by in 9.4-22.6\% of patients with PNES ${ }^{23-25}$. In our study, epileptic seizures were accompanied by PNES in 16 of 91 (24.2\%) patients.

In our study, no seizure by induction was observed in 9 patients whose follow-up diagnosis was PNES. It was hypothesized that patients might have PNES because of other factors such as home videos, or the definition of patients and their relatives and attack-triggering elements were not formed in video-EEG setting. We are of the opinion that a positive patients-physician relationship may have positive impact on the patient's psychogenic seizure.

As a result, induction methods are negative due to ethical concerns, clearly deceptive methods, deterioration of the patient-physician relationship, and violation of trust. On the other hand, it is beneficial in terms of helping the diagnosis 
and avoiding AED side effects, unnecessary hospitalizations and high costs.

In the study by Chan et al., saline induction was compared with placebo. The induction success rate was $79.4 \%$ and for placebo $73.5 \%$, showing no statistical difference ${ }^{36}$. In the study conducted by Hoepner et al., photic stimulation and hyperventilation increased the number of seizures before EEG.
Consequently, simply providing accurate and clear information about provocation methods increased PNES ${ }^{37}$.

In conclusion, provocative methods are practical, cheap, and most of all, effective for patients to accept a diagnosis. It should be remembered that explaining the diagnosis is the first and most important step of the treatment in clinical practice, and careful patient-doctor communication has a positive impact on patient's prognosis.

\section{REFERENCES}

1. LaFrance Jr WC, Devinsky O. The treatment of nonepileptic seizures: historical perspectives and future directions. Epilepsia. $2004 \mathrm{Jun} ; 45$ Suppl 2:15-21. https://doi.org/10.1111/j.0013-9580.2004.452002.x

2. Lancman ME, Brotherton TA, Asconapé JJ, Penry JK. Psychogenic seizures in adults: a longitudinal study. Seizure. $1993 \mathrm{Dec}$ 1;2(4):P281-6. https://doi.org/10.1016/S1059-1311(05)80141-4

3. Benbadis SR, Hauser WA. An estimate of the prevalance of psychogenic non-epileptic seizures. Seizure. 2000 Jun;9(4):280-1. https://doi.org/10.1053/seiz.2000.0409

4. Martin R, Burneo JG, Prasad A, Powell T, Faught E, Knowlton R, et al. Frequency of epilepsy in patients with psychogenic seizures monitored by video-EEG. Neurology. 2003 Dec 23;61(12):1791-2. https://doi.org/10.1212/01.WNL.0000098890.13946.F5

5. Lesser RP. Psychogenic seizures. Neurology. 1996 Jun 1;46(6):14991507. https://doi.org/10.1212/WNL.46.6.1499

6. Asadi-Pooya AA. Psychogenic nonepileptic seizures: a concise review. Neurol Sci. 2017 Jun;38(6):935-40. https://doi.org/10.1007/s10072017-2887-8

7. Asadi-Pooya AA. Psychogenic nonepileptic seizures are predominantly seen in women: potential neurobiological reasons. Neurol Sci. 2016 Jun;37(6):851-5. https://doi.org/10.1007/s10072016-2481-5

8. Syed TU, LaFrance Jr WC, Kahriman ES, Hasan SN, Rajasekaran V, Gulati D, et al. Can semiology predict psychogenic nonepileptic seizures? Aprospective study. Ann Neurol. 2011 Jun;69(6):997-1004. https://doi.org/10.1002/ana.22345

9. Dworetzky BA, Bubrick EJ, Szaflarski JP, Force NST. Nonepileptic psychogenic status: markedly prolonged psychogenic nonepileptic seizures. Epilepsy Behav. 2010 Sep;19(1):65-8. https://doi. org/10.1016/j.yebeh.2010.06.052

10. Reuber M, Baker GA, Gill R, Smith DF, Chadwick DW. Failure to recognize psychogenic nonepileptic seizures may cause death. Neurology. 2004 Mar 9;62(5):834-5. https://doi.org/10.1212/01. WNL.0000113755.11398.90

11. Leiss AA, Ross MA, Summers AK. Psychogenic seizures: ictal characteristics and diagnostic pitfalls. Neurology. 1992 Jan;42(1):959. https://doi.org/10.1212/WNL.42.1.95

12. Benbadis SR, LaFrance Jr WC, Papandonatos GD, Korabathina K, Lin K, Kraemer HC. Interrater reliability of EEG-video monitoring. Neurology. 2009 Sep 15;73(11):843-6. https://doi.org/10.1212/ WNL.0b013e3181b78425

13. Goyal G, Kalita J, Misra UK. Utility of different seizure inductionprotocols in psychogenicnonepilepticseizures. Epilepsy Res. 2014 Aug;108(6):1120-7. https://doi.org/10.1016/j. eplepsyres.2014.02.015

14. Walczak TS, Williams DT, Berten W. Utility and reliability of placebo infusion in the evaluation ofpatients withseizures. Neurology. 1994 Mar;44(3 Pt 1):394-9. https://doi.org/10.1212/WNL.44.3_Part_1.394

15. Selwa LM, Geyer J, Nikakhtar N, Brown MB, Schuh LA, Drury I. Nonepileptic seizure outcome varies by type of spell and duration of illness. Epilepsia. 2000 Oct;41(10):1330-4. https://doi. org/10.1111/j.1528-1157.2000.tb04613.x

16. Gudmundsson O, Prendergast M, Foreman D, Cowley S. Outcome of pseudoseizures in children and adolescents: a 6-year symptom survival analysis. Dev Med Child Neurol. 2001 Aug 29;43(8):547-51. https://doi.org/10.1017/S0012162201000986

17. Dhiman V, Sinha S, Rawat VS, Vijaysagar KJ, Thippeswamy H, Srinath $S$, et al. Children with psychogenic non-epileptic seizures (PNES): a detailed semiologic analysis and modified new classification. Brain Dev. 2014 Apr 1;36(4):P287-93. https://doi.org/10.1016/j. braindev.2013.05.002

18. Reuber M, Elger CE. Psychogenic non epileptic seizures: review and update. Epilepsy Behav. 2003 Jun 1;4(3):P205-16. https://doi. org/10.1016/S1525-5050(03)00104-5

19. Parra J, Kanner AM, Iriarte J, Gil-Nagel A. When should induction protocols be used in the diagnostic evaluationof patients with paroxysmal events? Epilepsia. 1998 Aug;39(8):863-7. https://doi. org/10.1111/j.1528-1157.1998.tb01181.x

20. Dericioğlu N, Saygi S, Ciğer A. The value of provocation methods in patients suspected of having non-epilepticseizures. Seizure. 1999 May;8(3):152-6. https://doi.org/10.1053/seiz.1999.0277

21. Bora IH, Taskapilioglu O, Seferoglu M, Kotan OV, Bican A, Ozkaya $G$, et al. Sociodemographics, clinical features, and psychiatric comorbidities of patients with psychogenic nonepileptic seizures: experience at a specialized epilepsy center in Turkey. Seizure. 2011 Jul 1;20(6):P458-61. https://doi.org/10.1016/j.seizure.2011.02.007

22. Demir AB, Bora I. A new review of seizure types in psychogenic nonepileptic status. J Exp Clin Med. 2014 Jun 5;31(1):25-9. https://doi. org/10.5835/jecm.v1i31.1009002850

23. Bendabis SR. Differential diagnosis of epilepsy. Continuum (Minneap Minn). 2007;13(4):48-70.

24. Duncan R, Oto M, Martin E, Pelosi A. Late onset psychogenic nonepileptic attacks. Neurology. 2006 Jun 13;66(11):1644-7. https:// doi.org/10.1212/01.wnl.0000223320.94812.7a

25. Benbadis SR. Provocative techniques should be used for the diagnosis of psychogenic nonepileptic seizures. Epilepsy Behav. 2009 Jun 1;15(2):P106-9. https://doi.org/10.1016/j.yebeh.2009.02.002

26. Kaczmareka, I, Starczewskab M, Winczewska- Wiktorb A, Steinbornb B. Sensitivity and specificity of induction of psychogenic nonepileptic seizures in children and adolescents. Seizure. 2020 Aug 1;80:P278-80. https://doi.org/10.1016/j.seizure.2020.05.012

27. Slater JD, Brown MC, Jacobs W, Ramsay RE. Induction of pseudoseizures with intravenous saline placebo. Epilepsia. 1995 Jun;36(6):580-5. https://doi.org/10.1111/j.1528-1157.1995.tb02571.x

28. Stagno SJ, Smith ML. The use of placebo in diagnosing psychogenic seizures: who is being deceived? Semin Neurol. 1997;17(3):213-8. https://doi.org/10.1055/s-2008-1040931

29. Varela HL, Taylor DS, Benbadis SR, Selim R. Short-term outpatient EEGvideo monitoring with induction in a veteransadministration population. J Clin Neurophysiol. 2007 Oct;24(5):390-1. https://doi. org/10.1097/WNP.0b013e31812f6c11 
30. Gates JR. Provocative testing should not be used for nonepileptic seizures. Arch Neurol. 2001 Dec;58(12):2065-6. https://doi. org/10.1001/archneur.58.12.2065

31. Bradley WG, Daroff RB, Fenichel GM, editors. Neurology in clinical practice: principles of diagnosis and management. 4th ed. Philadelphia (PA): Butterworth-Heinemann; 2004. 2545p.

32. Park EG, Lee J, Lee BL, Lee M, Lee J. Paroxysmal nonepileptic events in pediatric patients. Epilepsy Behav. 2015 Jul 1;48:P83-7. https://doi. org/10.1016/j.yebeh.2015.05.029

33. Bodde NMG, Brooks JL, Baker GA, Boon PAJM, Hendriksen JGM, Mulder OG, et al. Psychogenic non-epileptic seizures-definition, etiology, treatment andprognostic issues: a critical review. Seizure. 2009 Oct 1;18(8):P543-53. https://doi.org/10.1016/j. seizure.2009.06.006

34. Iriarte J, Parra J, Urrestarazu E, Kuyk J. Controversies in the diagnosis and management of psychogenic pseudoseizures. Epilepsy Behav. 2003 Jun 1;4(3):P354-9. https://doi.org/10.1016/S15255050(03)00113-6

35. Benbadis SR, Agrawal V, Tatum WO 4th. How many patients with psychogenic nonepileptic seizures also have epilepsy? Neurology. 2001 Sep 11;57(5):915-7. https://doi.org/10.1212/WNL.57.5.915

36. Chen DK, Dave H, Gadelmola K, Jeroudi M, Fadipe M. Provocative induction of psychogenic nonepileptic seizures: Noninferiority of an induction technique without versus with placebo. Epilepsia. 2018 Nov;59(11):161-5. https://doi.org/10.1111/epi.14570

37. Hoepner R, Labudda K, Schoendienst M, May TW, Bien CG, Brandt C. Informing patients about the impact of provocation methods increases the rate of psychogenic nonepileptic seizures during EEG recording. Epilepsy Behav. 2013 Sep 1;28(3):P457-9. https://doi. org/10.1016/j.yebeh.2013.06.009 